\title{
Awareness, Interest, Sensitivity, And Advocacy - AISA: An Educational 'Take-Away' For Business Ethics Students
}

Brent Smith, Saint Joseph's University, USA

\begin{abstract}
It has been nearly 30 years since business schools began providing formal courses in business ethics to their students. In that time, the public has witnessed countless cases of business misconduct, often performed by these students. Scholars and researchers agree that ethics education is important, yet they disagree about how it should be taught, what specific content themes should comprise it, and what students should take away from their training. Compounding this matter, students may be expected to grasp, retain, and apply on-demand various ethical theories and rules, which ultimately make them less intuitive, interesting, and practicable. In response to these issues, the AISA model was developed to serve as an ethics educational takeaway that students can easily comprehend and apply across a variety of situations dealing with ethics and social responsibility. An introduction to the AISA model and its applications are presented here.
\end{abstract}

Keywords: business ethics; education; common good; social responsibility

\section{INTRODUCTION}

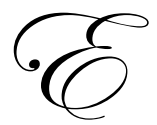

thics has been pervasive to liberal arts studies throughout US higher education since the 19th century. However, since the start of the 20th century and the industrial age, ethics became a rather marginalized discipline, particularly in the area of business/industrial organization (Hastings Center 1980). Following published studies of society's ethical health, the Hasting Center exhorted higher education to re-integrate explicitly ethics education into their curricula. Many business scholars responded to these exhortations and recommended the creation or adoption business-specific ethics courses for undergraduate students (Weber, 1990; Brenkert 2008; Frederick and Hoffman, 1991; and Piper, Gentile and Park, 1993).

Since the Hastings reports, as of $1995,29 \%$ of business schools mandated that students take at least one separate course in the business curriculum. The remainder has chosen to offer ethics electives, integrate ethical content into courses, or provide no ethical instruction at all (Solberg, Strong, and McGuire, 1995). Although the Association to Advance Collegiate Schools of Business (AACSB) and many business schools have responded to the situation by mandating required business ethics courses, problems do exist (Borkowski and Ugras, 1998; Greenman and Sherman, 1999; and others).

The experiences of teaching and learning can be particularly challenging for instructors and students, respectively. For example, despite the importance of business ethics to business curricula, textbooks on the subject vary dramatically in their content. A sampling of texts from DeGeorge (1994), Fritzsche (1997), Shaw and Barry (1997), Hartman (1998), and Ferrell, Fraedrich, and Ferrell (2000) shows no general agreement about the goals or contents that should be covered or how. Hence, it is a foreseeable consequence that business students may exit their undergraduate programs and enter the professional world with very different, or even divergent, notions about the meaning, purpose, and significance of business ethics. 
Compounding the challenges that ensue from diverse textbooks, business students are also exposed to myriad models of ethical behavior. Encompassing duty-based, virtue-based, consequence-based, and other theories, students can be overwhelmed with understanding these theories and knowing when or how they should be applied in real-world situations.

\section{Stakeholder Theory: A Perspective for Everyday People}

Amidst the plethora of theoretical and pedagogical approaches for transmitting ethical values into the classroom, students essentially depend upon foundational concepts that can help them achieve a more holistic grasp of the ethics. For example, how readily and frequently might students recall Kant's categorical imperative or "veil of ignorance"? Furthermore, how many corporate training programs and formal ethics policies purposefully articulate the tenets of deontological or utilitarian ethics? And more importantly, how many professional without business degrees already have a acceptable comprehension of right and wrong, despite not having been "schooled" in ethical theory? In short, while ethics is important, its spirit is not available to only college and university students. Given that many agents and observers of corporate, financial, and other business misconduct are products of formal business education, it begs the question: What do professionals really retain and apply regarding ethics and the common good?

Clearly, ethics is critical to stable functioning of business and society. Ethicists have offered many rationale and perspectives to help individuals act and interact more ethically with one another in mind. One such perspective, known as the stakeholder perspective (Freeman, 1984), allows students to understand their roles (e.g., employees, managers) in relations to others (e.g., colleagues, customers, shareholders). In addition, the stakeholder perspective is an appropriate framework for teaching all major areas of business ethics - ethical leadership, ethical decision making, corporate governance, and business and society - as specified by AACSB International (Ferrell and Ferrell 2005). Taking a broader worldview, this perspective reflects a broader, more virtuous concept known as the common good.

\section{AISA: Awareness, Interest, Sensitivity, and Advocacy}

"A theory is the more impressive the greater the simplicity of its premises, the more different are the kinds of things it relates, and the more extended the range of its applicability." - Albert Einstein, Physicist

Over the last few decades following the formalized integration of business ethics education into business curricula, the public has witnessed and suffered countless cases of corporate immoral, unlawful, and irresponsible conduct. In reaction to this situation, Giacalone and Thompson (2006) note, "In this environment, how we sensitize our students (i.e., how we teach our students about business ethics and social responsibility) becomes central to the influence we might have in shaping their thinking" (p. 266). Still, many business students are educated through a web of theories and philosophies that make ethics seem problematically applicable or practicable. Robin and Reidenbach (1993) echo this concern declaring that "the direct application of popular moral philosophies such as deontology or utilitarianism to ethical questions ... falls short in providing necessary guidance" (p. 97).

In response to these perspectives, I developed a basic framework for helping business students and professionals grasp the spirit of ethics and social responsibility without the complexities of ethical theory, thought, and jargon. This approach, called AISA (pronunciation: $\backslash$ ' $\overline{-}-$, sol), is indeed influenced by established ethical thought, though it does not explicitly burden ethics students with their rote memorization (Figure 1). AISA stands for progressive states of ethical engagement: Awareness (A), Interest (I), Sensitivity (S), and Advocacy (A). It embodies the stakeholder perspective and common good principle, enabling individuals to identify, query, and evaluate their positions in the connected presence of others. Metaphorically speaking, AISA is equivalent to a automobile in that any person can learn how to operate it, despite lacking underlying technical knowledge about how its engineering (e.g., ethical theory). At least two reasons support the points within this metaphor. First, educators generally complain that their students do not retain many of the lessons they are taught. Second, business misconduct is often committed by professionals who were formally trained in business ethics as part of the education. Reflecting the significance of the reasons Giacalone and Thompson (2006) assert, "the inoculations to immoral behavior that we provide students, often through the direction of philosophical strategies and notions of 
social responsibility, are inadequate .... this stream of bad news that leaves us asking how teaching ethics and social responsibility might mitigate the problem" (p. 266).

Figure 1: AISA Model

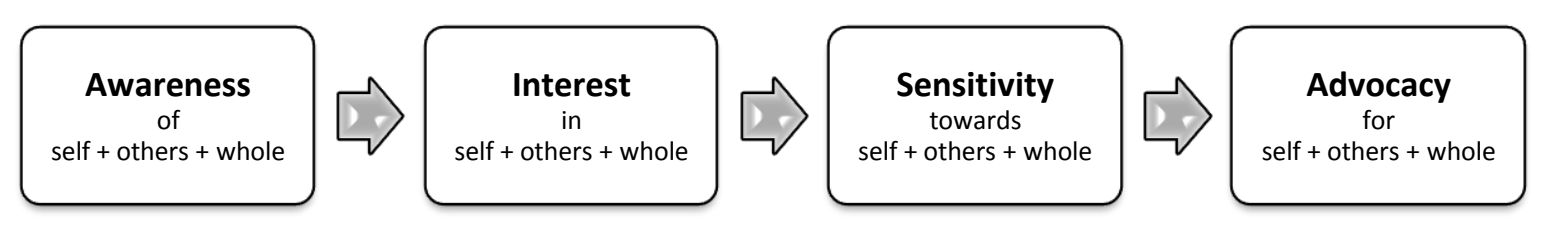

AISA was developed to provide students a "takeaway" from their ethics education experience. In that light, it can be used for pedagogy in concert with conventional classroom articulations of ethical theories. AISA is not intended to represent the culmination of a student's formal ethics education, rather it reflects a culmination of the key points to which a student has hopefully been exposed in that education, such as being professionally accountable, honoring fiduciary obligations, providing truthful information, protecting consumers, respecting human research subjects, and minimizing harm to the environment.

\section{AISA Component Definitions}

As shown above, AISA is comprised of four component parts, which serve as milestones directing individuals towards ethical behaviors that reflect the common good. These four parts, including (1) Awareness, (2) Interest, (3) Sensitivity, and (4) Advocacy, are defined below.

"Problems cannot be solved at the same level of awareness that created them." - Albert Einstein, Physicist

Awareness

Awareness is defined as having or showing realization, perception, or knowledge (Merriam-Webster, 2009). As noted by Jones (1991), ethical action hinges upon an issue-contingency. That is, one must be aware of an ethical issue before one can actually respond to it. Individuals can achieve awareness of stakeholders and their issues through formal education, immersion experience, and exposure via news or other media.

Interest

Interest is defined as participation in advantage and responsibility (Merriam-Webster, 2009). From the stakeholder perspective, ethics and social responsibility concretize the mutual rights, liberties, and obligations yoking, or bonding, all individuals in business and society.

Sensitivity

Sensitivity exemplifies responsiveness to the attitudes, feelings, or circumstances of others (American Heritage Dictionary, 2000). In the stakeholder context, sensitive individuals are receptive, thoughtful, and alert regarding issues that might affect their relationships with others. This concept is captured well by the sub-Saharan African concept of umntu ngumntu ngabanye, or "a person is a person through others" (Mangaliso, 2001, p. 24).

Advocacy

Advocacy is defined as the act of pleading, arguing, or supporting in favor of a cause, idea, or policy. As discussed in the next section, advocacy in the AISA framework means that individuals take up a higher cause beyond their own individual or local priorities. International Jesuit education trains students to be advocates of 
solidarity for the real world as "men and women for others" (a term and concept originated by Pedro Arrupe in his address to European Jesuit schools on July 31, 1973).

\section{AISA Explained}

“Would we want to do business with ourselves?” - Electronic Data Systems (Abend, 1988)

As shown in Figure 1, the AISA model lends itself to rather intuitive comprehension by means of its four basic components. Collectively, these components form a sequence of turning points, or milestones, leading to an individual's engagement of the common good that ties stakeholders together (Figure 2). There are two approaches — forward and backward — for interpreting, and thus, teaching with the model.

By the forward approach, individuals must achieve awareness of a particular position, issue, or cause (e.g., their own or others') before they can develop interest in it. Consequently, individuals must have already taken interest in a particular position, issue, or cause before they can become sensitive towards it. Finally, individuals must be sensitive towards a particular position, issue, or cause before they can take up advocacy for it.

Figure 2: AISA and the Common Good

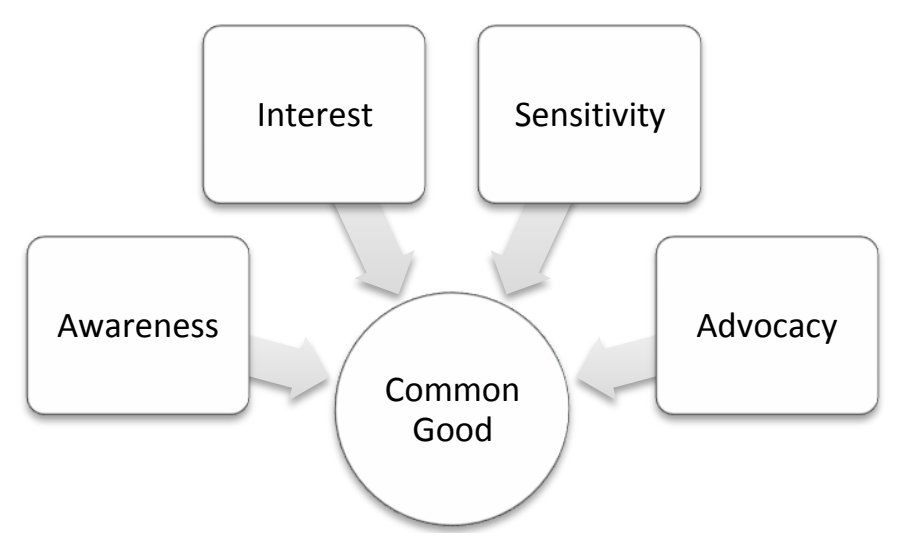

The backward approach borrows the "think forward, reason backward" wisdom of economic game theory. This alternative ends-oriented approach offers a perhaps clearer explanation of AISA. Individuals advocate only for the positions, issues, or causes of self/others towards which they have become sensitive. Individuals are sensitive to only the positions, issues, or causes in which they have taken interest. Reflecting the issue-contingency concept of Jones (1991), individuals can take interest only in those positions, issues, or causes of which they have been made aware.

Substantial indirect evidence of the logic for explaining AISA can be observed in the "competition" among charities, social causes, and various advocacy groups that often target recruitment and fundraising efforts at similar populations. These cause-oriented competitors (e.g., Habitat for Humanity, Red Cross, UNICEF, and March of Dimes) often develop branding campaigns to create public awareness, capture public interest, cultivate public sensitivity, and compel public advocacy for their very causes. In essence, they realize that their focus on social responsibility cannot alone sustain or propel their endeavors.

Why does advocacy for personal, other, and community positions matter among stakeholders in business and society? Essentially, advocacy in the AISA framework calls upon individuals to acknowledge the authenticity of other stakeholders' priorities (for self, others, and the whole community). This advocacy is mutually and holistically inclusive of all principal stakeholders involved. In short, well-being becomes a universally constructed, pursued, and evaluated goal. When stakeholders are collectively oriented towards a common good they can 
proactively set and revise their agenda together, as needed, over time, and across different circumstances. AISA acknowledges the calls by Bok (1976) and Bishop (1992) for ethics approaches that require an awareness of one's own and other people's values. Therefore, as a twist on the consequence-based ethos, AISA interjects the inquiry: What kinds of ends reflect the common good? How does the common good include happiness for me/us AND her/him/them, based on what I/we and she/he/they value?

\section{Integrating AISA into Business Ethics Education}

Whether business programs require a specific business ethics course or simply encourage instructors to fit ethics components across their courses, business students can benefit from the AISA approach. Several reasons support this assertion.

First, AISA is intuitively comprehensible and, hence, relatively easy to recall. Second, AISA is rooted in the stakeholder perspective, which covers the four major areas of business ethics - ethical leadership, ethical decision making, corporate governance, and business and society - as specified by AACSB International (Ferrell and Ferrell 2005). Third, AISA allows for the discussion of other ethical principles, such utilitarianism (e.g., greatest happiness for greater number of people), enlightened self-interest (e.g., pursuing one's own interests in ways that minimize harms to others), and the Golden Rule (e.g., treat others as you wish them to treat you). Relevant beyond Western-style societies, ethics teaching with AISA can be inclusive of various cultural and religious values. For example, teachers and students familiar with different rules of reciprocity can discuss how ethics and social responsibility resonant within their expectations for professional conduct. Sample rules that work well with the AISA's self/others/whole standard include the Confucian analects (e.g., Never impose on others what you would not choose for yourself), Taoist principles (e.g., Regard your neighbor's gain as your own gain, your neighbor's loss as your own loss, T'ai Shang Kan Ying P'ien), or Buddhist virtue (e.g., place oneself in the place of another). Fourth, in light of the need for ethics to become truly global, business ethics education must first become less exclusive to Western ideals and more inclusive of multicultural ones. In essence, AISA is a scalable model that can enable narrow rule-specific or broad pluralistic ethics discussion.

\section{General Business Applications: Interest and Impact}

Organizations are, in large part, reflections of the value systems practiced and espoused by senior management. Companies engaged in business seek customers and profits, though in many regards, the former is treated as a means to the latter. Given the general distrust that consumers feel towards companies, applications of the AISA model could help business leaders develop or enhance their consciousness, literacy, and effect in matters related to the common good defined by consumers. As a result, they would be better prepared to act proactively in the interest of the common good, whether preemptively or reactively.

Bok (1976) and Bishop (1992) call for ethics that require an awareness of one's own and other people's values. Given that veteran employees and new-hires bring their own individual values to ethical situations (Forsyth, 1992; Yu and Zhang, 2006; and others), managers must carefully handle an unpredictable diversity of overt and subtle positions on various daily business issues. While corporate training, if available and required, may educate employees about official ethics codes and policies, perhaps, group case study discussions framed within the AISA context would encourage employees to learn how and why ethics matters to companies and the consumers they serve. For example, discussion could lead the trainees to identify the stakeholders, enact role-plays to understand their issues, and debate to work towards common good solutions that satisfy corporate, consumer, and other objectivities whilst acknowledging and minimizing harms. Such an approach could give ethics a face and make it more relevant than simply lengthy prose in an employee handbook.

The AISA-oriented discourse can take place within the boundaries of a company or between a company and its customers. Wherever it occurs, that discourse should involve some reflection on one's connections to other stakeholders, since that represents these connections set up a starting/turning point for contemplating ethical approaches. Some points of reflection for the business employee might include: 
1. Aside from the values of the company, how well do we know the values of employees, customers, and partners? How much do their values impact the ethics of our business practices?

2. Other than our managers, what do our customers really expect from us? Have we ever asked? How much do we really care about their expectations? Are we able to advocate any customer expectations to our managers?

3. What mechanisms do we have in place for receiving, resolving, and learning from customer complaints about our product claims or ethical practices? What is the nature of the legitimate criticisms we have via consumer complaints, regulatory audits, or other process?

4. Have we carefully studied whether our products or practices have an undesirable or manageable impact on consumers and/or the community-at-large?

5. What role do people in my/our profession play in justifying the public distrust of our industry? What actions have I/we taken to address this role? Do we ever remain silent when our peers perform acts of ethical misconduct?

6. Does our industry or company expose itself to situations that may lead employees behave unethically? Does our company place too great a priority on profit-centered performance versus ethically-centered performance?

7. How well do our responses to ethical issues reflect our understanding of the common good?

8. Based on the above questions, would we do business with ourselves?

Essentially, these general questions are applicable to the primary business functions in accounting, finance, marketing, operations, and general management. They challenge managers and employees in these functions to ascertain the levels of awareness, interest, sensitivity, and advocacy within themselves and their companies. Since business ethics is applied, its successful application necessarily depends upon how well it is directed (by self/others/all), evaluated (by self/others/all), and monitored (by self/others/all).

Discussion for Learning without Judgment

"Be not ashamed of mistakes and thus make them crimes." - Confucius

"It does not matter how slowly you go as long as you do not stop." - Confucius

As noted, the AISA model can serve as a collective learning tool in formal ethics theory education, ethics case study discussions, corporate ethics training, and so forth. Since it is holistic in nature, depending on input from a variety of stakeholders, its application should be managed with care. Collective learning through AISA requires that all parties sustain openness to honest, sincere discourse about their positions and values. This discourse, whether it occurs in a transaction, classroom, complaint forum, or town hall meeting must illicit learning about how to achieve common good, not judgment for falling short of it. Ethics is about working towards the common good, recognizing that all persons are continual works-in-progress.

\section{CONCLUSION AND IMPLICATIONS}

The AISA model was developed to help business students and practitioners across cultures and disciplines appreciate the ideals of social responsibility and the common good. It does not explicitly advance any particular ethical theory or require learners to study them. With the tide of globalization taking form across myriad cultures and traditions of the developed and developing worlds, AISA allows for Western and non-Western articulations of ethics or local equivalents. Furthermore, AISA challenges and enables individuals (e.g., consumers, employees, managers, public policy makers) to become self-learners who actively attempt to discern how they affect the lives of others. Hence, the AISA model can be used in conjunction with a variety of teaching philosophies, such as service learning, Catholic Social Teaching, or ethnographic immersion.

Clearly, better approaches and results are needed from today's business curricula. As Giacalone and Thompson (2006) critique, the thrust of these curricula "fails to focus on issues of human well-being: what we teach our students about how people should be treated, their rights, and the immutable idea that concerns for well-being always precede profit" (p. 272). 
Based on the notion that ethics is both personal and learned (Sparks and Hunt 1998), today's students could benefit from AISA as an "educational take-away" threaded with concern for well-being. Additionally, business ethics education must reflect the ideals of "thinking globally and acting locally." This means that business ethics education must integrate more diverse multicultural perspectives. The AISA model enables such integration while still respecting currently prevailing perspective, such as stakeholder theory, utilitarianism, and enlightened selfinterest. Debate persists about whether and how ethics can really be taught. AISA reflects the position that what must really persist is a collective quest toward a pluralistically defined common good.

\section{AUTHOR INFORMATION}

Brent Smith is Assistant Professor of Marketing in the Erivan K. Haub School of Business at Saint Joseph's University (Philadelphia, Pennsylvania). His teaching and research interests include international marketing, marketing strategy, and marketing ethics.

\section{REFERENCES}

1. $\quad$ Abend, J. 1988. Corporate ethics: An overview. New Accountant 4 (1): 4-11.

2. $\quad$ advocacy. 2009. In Merriam-Webster Online Dictionary. http://www.merriam-webster.com/dictionary/awareness

3. $\quad$ awareness. 2009. In Merriam-Webster Online Dictionary. http://www.merriam-webster.com/dictionary/awareness

4. $\quad$ interest. 2009. In Merriam-Webster Online Dictionary. http://www.merriam-webster.com/dictionary/awareness

5. $\quad$ sensitivity. 2009. In Merriam-Webster Online Dictionary. http://www.merriam-webster.com/dictionary/awareness

6. Bishop, Terrence R. 1992. Integrating business ethics into an undergraduate curriculum. Journal of Business Ethics 11 (4): 291-99.

7. Bok, Derek. C. 1976. Can ethics be taught? Change (October): 26-30.

8. Borkowski, S.C. and Y.J. Urgas. 1998. Business students and ethics: A meta-analysis, Journal of Business Ethics 17 (August): 1117-27.

9. Brenkert, George G. 2008. Marketing ethics. Malden, MA: Blackwell Publishing.

10. DeGeorge, Richard T. 1994. Business Ethics, $4^{\text {th }}$ Ed. New York: Macmillan Publishing Company.

11. Ferrell, O.C. and Linda Ferrell. 2005. Understanding how to teach business ethics by understanding business ethics. In Sheb L. True, O.C. Ferrell, and Linda Ferrell Fulfilling Our Obligations: Perspectives on Teaching Business Ethics, Kennesaw State University Press.

12. Ferrell, O.C., John Fraedrich, and Linda Ferrell. 2000. Business Ethics: Ethical Decision Making and Cases, $4^{\text {th }} E d$., Boston: Houghton Mifflin Company.

13. Forsyth, D. R. 1992. Judging the morality of business practices: The influence of personal moral philosophies. Journal of Business Ethics, 11 (May): 461-70.

14. Frederick, Robert E. and W. Michael Hoffman. 1991. Business ethics in the curriculum: A dialogue with a stranger in a strange land. The Mid-Atlantic Journal of Business 27 (1): 5-16.

15. Fritzsche, David. 1997. Business Ethics, New York: McGraw-Hill.

16. Giacalone, Robert A. and Kenneth R. Thompson. 2006. Academy of Management Learning \& Education 5 (3): 266-277.

17. Greenman, F.E. and J.F. Sherman III. 1999. Business school ethics - An overlooked topic. Business and Society Review 104 (Summer): 171.

18. Hartman, Laura Pincus. 1998. Perspectives in Business Ethics, Chicago: Irwin McGraw-Hill.

19. Hastings Center, The. 1980. The Teaching of Ethics in Higher Education, Hastings-on-Hudson, NY: Hastings Center.

20. Jones, Thomas M. 1991. Ethical decision making by individuals in organizations: An issue-contingent model. Academy of Management Review, 16 (April): 366-95.

21. Mangaliso, M.P. 2001. Building competitive advantage from Ubuntu: management lessons from South Africa. Academy of Management Executive 15 (3): 23-33. 
22. Piper, Thomas R., Mary C. Gentile, and Sharon Daloz Park. 1993. Can Ethics be Taught? Perspectives, Challenges, and Approaches, Boston: Harvard Business School.

23. Shaw, William and Vincent Barry. 1997. Moral Issues in Business, $7^{\text {th }}$ Ed., Belmont, CA: Wadsworth.

24. Weber, James. 1990. Measuring the impact of teaching ethics to future managers: A review, assessment, and recommendations. Journal of Business Ethics 9: 183-90.

\section{NOTES}

